\title{
Mulleres galegas na Residencia de Señoritas de Madrid, "cando van, van como rosas..."
}

\section{Galician women in the Residencia de Señoritas of Madrid, "On going away, they are like roses..."}

Raquel VÁZQUEZ RAMIL Escola Universitaria de Maxisterio CEU-Vigo

A memoria do meu avó Manuel Ramil Casal, que me regalou o primeiro caderniño escolar e pagou a miña tese doutoral

RESUMO: Nese artigo se estudian as mulleres galegas ou vinculadas con Galicia que viviron na Residencia de Señoritas de Madrid entre 1915 e 1936. En primeiro lugar se fai un percorrido pola historia do centro e as vicisitudes da súa creación no seo da Junta para Ampliación de Estudos, centrándonos de seguido nas galegas que nel viviron. Tras un acercamento estatístico, analizamos as súas traxectorias profesionais e vitais cos datos extraídos de fontes primarias do arquivo da Residencia de Señoritas e de fontes bibliográficas e hemerográficas. Deixamos abertas as conclusións en espera de futuras e necesarias aportacións ao tema.

PALABRAS CLAVE: Residencia de Señoritas, educación da muller, Institución Libre de Enseñanza, Junta para Ampliación de Estudios e Investigaciones Científicas, mulleres galegas.

ABSTRACT: In this paper it will be presented a study about the Galician or linked to Galicia women which lived in the Residencia de Señoritas in Madrid between 1915 and 1936. First, it will be reviewed the history of the Residencia and its peculiarities into the scheme of the Board for Advanced Studies, focusing on the Galician women that lived there. After an statistical approach, we study the careers and lives of the Galician residents working with data extracted from primary sources of the Residencia de Señoritas' Archive and also from bibliographic and newspaper sources. We don't close conclusions waiting for future and necessary contributions to the subject.

KEY WORDS: Residencia de Señoritas, Women's education, Institución Libre de Enseñanza, Board for Advances Studies and Scientific Research, Galician women. 


\section{A Residencia de Señoritas de Madrid}

A Junta para Ampliación de Estudios (JAE), entidade educativa e de fomento da investigación creada por R.D. de 11 de xaneiro de 1907', tiña entre os seus fines potenciar as relacións científicas co estranxeiro a través da concesión de pensións ou bolsas de estudio, soster centros de ensaios educativos e abrir residencias nas que completar a educación dos estudantes con medios de cultura axeitados e unha convivencia enriquecedora. En 1910 a JAE crea unha Residencia de Estudiantes en Madrid para atender ao último aspecto; a chamada Residencia de Estudiantes abre as súas portas en outubro do ano 2010 en dúas casas da madrileña rúa de Fortuny con capacidade para dezasete prazas; a dirección do centro encárgase a un discípulo de Giner de los Ríos, Alberto Jiménez Fraud. A Residencia foi un éxito dende o primeiro momento, o cal se explica polo elevado número de estudantes que nos primeiros anos do século XX se desprazaban a Madrid para cursar carreiras na Universidade Central, que monopolizaba os estudios de doutoramento.

A Residencia de Estudiantes foi ampliando as súas instalacións co aluguer de casas contiguas na mesma rúa de Fortuny, ata acadar unha capacidade para cen residentes en 1912, pero a crecente demanda impoñía unha ampliación da obra e, sobre todo, una reorganización da mesma, como se expresa nas Memorias da propia Junta:

En efecto, la Junta desearía consolidar este primer ensayo, amenazado de una grave crisis por hallarse en venta los hoteles donde la Residencia se ha instalado, mediante su adquisición y la de otros contiguos, y comenzar en seguida, en terreno amplio y apropiado y a conveniente distancia del centro, la construcción de casas especialmente destinadas a constituir nuevos grupos, asegurando así el aire puro y el espacio suficiente para bibliotecas, laboratorios, campos de juego, piscinas y demás complementos de cada colonia².

En 1913 o Ministerio de Instrucción Pública emprende a construción de un grupo de edificios destinados a Residencia de Estudiantes nos terreos dos Altos do Hipódromo ${ }^{3}$. As obras remátanse dous anos despois e en outubro de 1915 a Residencia de Estudiantes

1 A Junta para Ampliación de Estudios e Investigaciones Científicas se creou por Real Decreto de 11 de xaneiro de 1907, inserto na Gaceta de Madrid no 15, de 15 de xaneiro de 1907, pp. 165-167. Era ministro de Instrucción Pública Amalio Gimeno no gabinete liberal de Vega de Armijo. A redacción do proxecto da Junta atribúese a José Castillejo Duarte, que será o secretario, asesorado moi directamente por Francisco Giner de los Ríos. Véase: Vázquez Ramil, Raquel (2012), Mujeres y educación en la España contemporánea: la Institución Libre de Enseñanza y la Residencia de Señoritas de Madrid, Madrid, Akal, p. 83.

2 Junta para Ampliación de Estudios (1912), Memoria correspondiente a los años 1910 y 1911, Madrid, Ministerio de Instrucción Pública, pp. 214-215.

3 En 1913 se encargou do proxecto da nova Residencia de Estudiantes o arquitecto de orixe galega Antonio Flórez Urdapilleta, que pouco antes firmara a construcción das Escolas Froebel de Pontevedra. Antonio Flórez dirixiu a construcción dos pabellones xemeos, destinados a dormitorios, e do pabellón trasatlántico. En 19150 sustituiu ao frente das obras Francisco Javier Luque. Guerrero, Salvador, «Antonio Flórez Urdapilleta», en: Junta para Ampliación de Estudios. Centenario (2008), El laboratorio de España. La Junta para Ampliación de Estudios 1907-1939, Madrid, Sociedad Estatal de Conmemoraciones Culturales, pp. 332-333. Véase también: Porto Ucha, Anxo S. "La creación de una escuela de párvulos "Sistema Froebel" en la ciudad de Pontevedra", en: Naya Garmendia, Luis M. y Dávila Balsera, Paulí (2005), La infancia en la historia: espacios y representaciones, San Sebastián, Erein, Vol. I, pp. 367-376. 
se traslada as súas novas dependencias dos Altos do Hipódromo. As casas que ata entón ocupara na rúa Fortuny quedan baleiras, e a JAE decide aproveitalas para instalar nelas un proxecto arriscado naquel momento, unha residencia para mulleres que acudían a Madrid a estudar ou a formarse. E así no outono de 1915 nace o Grupo Femenino da Residencia de Estudiantes, máis expresivamente chamado Residencia de Señoritas, para diferéncialo mellor do seu homólogo masculino. A dirección da nova Residencia feminina encoméndase a María de Maeztu y Whitney ${ }^{4}$, mestra de orixe vasco e irmá do intelectual Ramiro de Maeztu, que fora ex-alumna de Unamuno na Universidade de Salamanca e de Ortega y Gasset na Escola Superior do Maxisterio de Madrid. As memorias da JAE xustifican a creación da nova Residencia con expresivas palabras e falan dun centro destinado:

a las muchachas que sigan sus estudios o preparen su ingreso en las Facultades universitarias, Escuela Superior del Magisterio, Conservatorio Nacional de Música, Escuela Normal, Escuela del Hogar u otros centros de enseñanza, y a las que privadamente se dediquen al estudio en bibliotecas, laboratorios, archivos, clínicas, etc. Quiere ofrecerles un hogar semejante al que tienen los estudiantes del Grupo universitario. ${ }^{5}$

A Residencia de Señoritas aproveita a oportunidade material das casas que o Grupo masculino deixa valeiras ao trasladarse aos Altos do Hipódromo. Como vimos, as instalación eran insuficientes para albergar un número considerable de residentes, pero na segunda década do século XX non eran moitas as mulleres que se desprazaban a Madrid a estudar; por outra banda, se trataba de hoteliños de tipo familiar que non foran deseñados para albergar estudantes e que, si ben contaban con pequenos xardíns, non tiñan campos de xogos nin estancias adecuadas para servizos comúns. A Residencia de Estudiantes comeza como experimento, en canto se ve que é un éxito a JAE emprende a construción de edificios ad hoc, e o Grupo Feminino convértese no novo experimento, aproveitando espazos ata demostrar a súa viabilidade.

Igual que sucedera ca Residencia de Estudiantes, a de Señoritas comeza con un pequeno grupo de dezasete residentes no curso 1915-1916; ao ano seguinte reúnense trinta residentes e o crecemento é continuo desde entonces. A Residencia de Señoritas non vai a ter edificios de nova planta para aloxar as mulleres que acudían a Madrid a estudar ou completar a súa cultura, pero contará ca colaboración material e humana dunha institución próxima xeográfica e ideolóxicamente, o International Institute for Girls in Spain ou Instituto Internacional, sostido por unha entidade misional congregacionalista e dedicado a educación das mulleres dende principios do século XX en Madrid6.

A partir de 1917 o Instituto Internacional cede, progresivamente, a Residencia de Señoritas en condicións económicas moi ventaxosas dous magníficos edificios nas rúas de

4 Sobre María de Maeztu, a súa vida e a súa labor ao frente da Residencia de Señoritas véase: Vázquez Ramil, R., Op. cit., pp. 129-154.

5 Junta para Ampliación de Estudios e Investigaciones Científicas, Memoria correspondiente a los años 1914 y 1915, Madrid, Imprenta de Fortanet, 1916, p. 303.

6 Un estudo exhaustivo do centro é o de Carmen de Zulueta, Misioneras, feministas, educadoras. Historia del Instituto Internacional, Madrid, Castalia, 1984. 
Fortuny 53 e Miguel Ángel 8, dotados de biblioteca, campos de xogos, xardíns, laboratorios, aulas de clase, dormitorios e salóns; e presta ademais a colaboración das súas profesoras americanas, que se encargan de materias novedosas no currículum educativo das mulleres como inglés, ximnasia, bailes, xogos, prácticas de laboratorio ou biblioteconomía.

Cando a Residencia de Señoritas abre as súas portas en outubro de 1915 é escaso 0 número de universitarias. De feito, o acceso da muller española a Universidade sen necesidade de pedir permiso a superioridade e cos mesmos dereitos que os alumnos varóns databa de 19107; era, por tanto, recente. No seguinte cadro pode verse a evolución da poboación universitaria feminina española entre 1915 e os anos da Segunda República8:

Poboación universitaria femenina en España

\begin{tabular}{|c|c|c|}
\hline Cursos & Cifras absolutas alumnas & Porcentaxe \% \\
\hline $1914-15$ & 90 & 0,45 \\
\hline $1919-20$ & 134 & 0,64 \\
\hline $1924-25$ & 1034 & 3,73 \\
\hline $1929-30$ & 1744 & 5,48 \\
\hline $1932-33$ & 2047 & 6,72 \\
\hline
\end{tabular}

O acceso da muller española a Universidade é anecdótico ata mediados dos anos vinte, nos tempos de relativa prosperidade económica da Ditadura de Primo de Rivera; durante a Segunda República apréciase unha tendencia a aceleración que será interrompida pola guerra.

A Universidade de Madrid (Central) é a única que nesa época ofrece todas as carreiras universitarias e a que monopolizaba os estudos de doutoramento, por iso tiña un grande peso porcentual en comparación cos restantes distritos universitarios, peso que tamén se reflexa no caso das alumnas. Temos constatado que en 1915 a Universidade de Madrid acollía ao $34,4 \%$ do total de alumnas matriculadas en centros universitarios, e que en

7 R.O. de 8 de marzo de 1910, derogatoria de la R.O. de 11 de xuño de 1888 que disponía que as mulleres foran admitidas nos estudios dependentes do Ministerio de Instrucción Pública e Belas Artes como alumnas de ensino privado e que cando alguna solicitase matrícula oficial, se consultase á Superioridade para que ésta resolvese según o caso e as circunstancias da interesada. A R. O. consideraba que as devanditas consultas, si non implicaban limitación de dereito, producían «dificultades y retrasos de tramitación, cuando el sentido general de la legislación de Instrucción Pública es no hacer distinción por razón de sexos, autorizando por igual la matrícula de alumnos y alumnas». Gaceta de Madrid no 68, miércoles 9 de marzo de 1910, pp. 497-498. Era ministro de Instrucción Pública o liberal Álvaro de Figueroa, conde de Romanones, quen 08 de mayo de 1910 firma o Real Decreto que creaba un Patronato e Residencia de Estudiantes dependente da JAE.

8 Elaboración propia a partir de datos dos Anuarios Estadísticos de España de 1916 a 1935. Nas cifras absolutas de alumnas figuran as matriculadas por oficial e libre; hai que ter en conta que nesa época incluiánse nos estudios universitarios os de odontoloxía (entón unha carreira corta) e matrona. 
1925 a porcentaxe era do $50 \%{ }^{9}$. Na capital de España había ademais outros centros aos que acudían un número significativo de mulleres, como a Escola de Estudios Superiores do Maxisterio (creada en 1909), o Real Conservatorio de Música e Declamación, a Escola do Fogar e Profesional da Muller, a Escola Central de Idiomas ou institucións particulares de diverso carácter.

\section{Mulleres galegas na Residencia de Señoritas de Madrid}

Si poucas, en termos relativos, eran as mulleres que chegaban aos estudos universitarios, no caso das galegas o panorama non desentoaba, mais ben ao contrario, teñíase de cores escuros ${ }^{10}$. E así, no curso $1915-1916$ eran nove as alumnas matriculadas na Universidade de Santiago (0,72\% do total de alumnos matriculados) e en $1930-31$ a cifra ascendera ata 163 alumnas $(7,75 \%$ do total).

En canto a presencia de mulleres galegas na Residencia de Señoritas, temos localizadas a trinta e tres entre as mil cento setenta e cinco ${ }^{11}$ que viviron no centro dende a súa creación en 1935 ata xullo de 1936, cando a guerra civil altera o funcionamiento do mesmo. No seguinte cadro figuran as residentes galegas, o seu lugar de orixe, os estudos cursados e os anos de estancia na Residencia: ${ }^{12}$

9 Vázquez Ramil, Raquel (2001), La Institución Libre de Enseñanza y la educación de la mujer en España: la Residencia de Señoritas (1915-1936), A Coruña, Lugami, p. 119.

10 Sobre 0 acceso retrasado da muller galega a alfabetización véase o exhaustivo traballo do profesor Narciso de Gabriel Fernández: Ler e escribir en Galicia. A alfabetización dos galegos e das galegas nos séculos XIX e XX, A Coruña, Universidade da Coruña, 2006, pp. 128-138. A chegada das galegas a Universidade de Santiago de Compostela foi estudiada por Isaura Varela González no seu libro La Universidad de Santiago (1900-1936). Reforma universitaria y conflicto estudiantil, Sada, Ediciós do Castro, 1989, esp. p. 181 e ss.

11 A relación nominal de residentes pode verse no noso libro: Mujeres y educación en la España contemporánea..., pp. 373-451.

12 Elaboración propia a partir de información dispersa do A.R.S.M (Arquivo da Residencia de Señoritas de Madrid), complementada con referencias do Arquivo da Edade de Plata (http://archivojae.edaddeplata.org/jae_ app/) e hemerográficas. 


\begin{tabular}{|c|c|c|c|}
\hline Residentes & Orixe & Estudos & Anos \\
\hline Concepción Alvarado González & A Coruña & \begin{tabular}{|l|l}
----- \\
\end{tabular} & \\
\hline Ángeles Alvariño González & Ferrol & Ciencias & $1934-35$ \\
\hline Isabel Barreiro Fernández & Vilagarcía & Esc. Sup. Maxisterio & $1927-32$ \\
\hline Carmen Bugallo Orozco & Pontevedra & Filosofía e Letras & $1932-35$ \\
\hline Consuelo Castelao Bernárdez & Ourense & Ciencias & $1931-35$ \\
\hline Pura Cendán González & Ferrol & Esc. Sup. Maxisterio & $1921-26$ \\
\hline Luisa Cuesta Gutiérrez & $\begin{array}{l}\text { Medina de Rioseco } \\
\text { (Valladolid) }\end{array}$ & \begin{tabular}{|l} 
Bibliotecaria Univ. \\
Santiago \\
\end{tabular} & $1927-28$ \\
\hline Manuela Rosa Doel Traseira & Lugo & $-\cdots---$ & $1934-35$ \\
\hline Blanca Dopico de Guernica & La Habana & Filosofía e Letras & $1928-29$ \\
\hline Francisca Fábregas & Vigo & ------- & $1933-34$ \\
\hline Concepción Fernández López & Lugo & Maxisterio & $1928-35$ \\
\hline Piedad Fernández López & Castro Caldelas & Esc. Sup. Maxisterio & $1919-24$ \\
\hline Rita Fernández Queimadelos & A Cañiza & Arquitectura & $1930-35$ \\
\hline Dolores Gallego García & Stgo de Compostela & Filosofía y Letras & $1925-28$ \\
\hline Gerarda Gallego García & Stgo de Compostela & |------- & $1925-28$ \\
\hline María García Iglesias & ------ & Mestra & $1931-32$ \\
\hline Raquel Lesteiro López & Pontevedra & Filosofía e Letras & $1921-22$ \\
\hline Celia Lesteiro López & Pontevedra & Corte e confección & $1921-22$ \\
\hline Alejandrina Loureiro & ------ & Canto & 1930-32 \\
\hline Maruja Mallo & Viveiro & Profesora de Dibuxo & $1935-36$ \\
\hline Mª Luz Morales Godoy & A Coruña & Escritora & -+-- \\
\hline Sofía Novoa Ortiz & Vigo & Piano e solfexo & $\begin{array}{l}1918-25 \\
1930-35 \\
\end{array}$ \\
\hline Paz Parada Pumar & Ourense & Mediciña & $1925-29$ \\
\hline Ángeles Pardo Celada & Becerreá & Mediciña & $1920-22$ \\
\hline Carmen Pardo Losada & Ourense & Esc. Sup. Maxisterio & $1925-28$ \\
\hline Paquita Penzol & ¿Castropol? & ----- & $1931-32$ \\
\hline Marina Peña-Rey Bouzas & Viascón (Pontevedra) & Farmacia & $1933-34$ \\
\hline Celsa Pérez Moreiras & León (orx. galega) & Farmacia & $1934-35$ \\
\hline Carmen Pernas Sanjurjo & Outeiro de Rei & $-\cdots$ & $1934-35$ \\
\hline María Portela Mengual & Vigo & Esc. Sup. Maxisterio & ------- \\
\hline Joaquina Rodríguez Caminero & Ourense & Filosofía e Letras & 1933-34 \\
\hline Manuela Salguero Camarero & A Coruña & |------ & $1933-35$ \\
\hline Aurora Sampedro Piñeiro & S. Pedro de Benquerencia & ¿Perito industrial? & $1930-35$ \\
\hline $\mathrm{M}^{\mathrm{a}}$ Antonina Sanjurjo Aranaz & Stgo de Compostela & Derecho & $\begin{array}{l}1931-32 \\
1933-34 \\
\end{array}$ \\
\hline Rosa Solórzano Rodríguez & A Coruña & Arquivos e bibliotecas & $1934-35$ \\
\hline Olimpia Valencia López & Baltar (Ourense) & Mediciña (doutoramento) & $1926-29$ \\
\hline
\end{tabular}


A presenza (documentada) de galegas na Residencia non é elevada e explícase por varios motivos:

(a) Galicia atópase xeograficamente lonxe de Madrid e contaba cunha das Universidades mais antigas e grandes de España, a de Santiago de Compostela, na que se ofrecía unha ampla gama de carreiras, entre elas a de Farmacia, moi feminizada dende a incorporación das mulleres ao ensino superior. Por tanto, as galegas que acudían a Madrid a estudar, dirixíanse fundamentalmente a centros que non existían no distrito de Santiago, como a Escola de Estudos Superiores do Maxisterio ou o Conservatorio Superior de Música e Declamación, ou ben para cursar o doutoramento ou a partir dun determinado momento para preparar oposición a corpos da administración do estado.

(b) Razóns económicas: as universitarias ou as mulleres que realizaban estudos especiais procedían polo xeral de sectores burgueses, con escasa representación na Galicia anterior á guerra civil. María de Maeztu manifestou en repetidas ocasións o seu interese de acoller na Residencia as mulleres de clase media con inquedanzas profesionais e ao efecto mantivo unha salientable política de bolsas de aloxamento, pero seguía a haber numerosos obstáculos para que as mulleres estudasen lonxe da súa cosa, e non solo económicos, senón de xeito moi claro sociais.

(c) Preferencia por outros ambentes: non todas as galegas que ían a Madrid a estudar se aloxaban na Residencia de Señoritas; había outras opcións: casas de familia, pensións, residencias relixiosas, etc. No último caso cabe salientar os establecementos da Institución Teresiana dende 1914, onde acudían sobre todo futuras mestras e alumnas da selecta Escola de Estudios Superiores do Maxisterio. ${ }^{13}$

Tratando o tema da procedencia das residentes, en 1929 María de Maeztu respondía así a unha simpática entrevista publicada no diario madrileño $A B C$ :

«-La mayor parte de las alumnas serán del Norte.

-No. Castilla, primero y, luego, Galicia.

$-i$ Castilla?

-Castilla, en la que siempre he tenido una fe ciega. León es una de las provincias más representadas. Los pueblecitos ofrecen, en proporción, bastante contingente. Vienen también, claro está, de todas las regiones. Por esta íntima convivencia provincial, la Residencia es buena escuela de nacionalismo». ${ }^{14}$

O maior número de residentes casteláns explícase pola amplitude xeográfica de Castela e porque Madrid era entonces o centro da rexión. A finais dos anos vinte había na

13 Un apreciable estudo comparativo entre a Residencia de Señoritas e a Institución Teresiana é o libro de Mercedes Montero, La conquista del espacio público: Mujeres españolas en la Universidad (1910-1936), Madrid, Minerva, 2009, pp. 77-103.

14 Rafael Villaseca, "Las que estudian. En la Residencia de Señoritas, hablando con María de Maeztu», $A B C$, Madrid, 07/04/1929, pp. 15-16. 
Residencia un grupo de residentes galegas equiparable al de estudantes vascas ou catalanas (estas últimas en menor medida e solo para facer o doutoramento ou carreiras moi específicas, pois Cataluña contaba con numerosas institucións educativas de todos os niveis e con centros modélicos de educación da muller dependentes da Mancomunitat). ${ }^{15}$ $\mathrm{Na}$ Residencia masculina foron maioría os andaluces (o director, Alberto Jiménez Fraud, era malagueño, como Giner de los Ríos) e os vascos, aínda que tamén foi significativa a presenza de asturianos, leoneses e galegos ${ }^{16}$.

\section{Traxectorias vitais e académicas das residentes vinculadas a Galicia}

Entre as galegas que viviron na Residencia de Señoritas destacan as que desenvolveron carreiras no ámbito do maxisterio ou a pedagoxía; outras cursaron as carreiras de Farmacia, Mediciña, Filosofía e Letras ou Ciencias; e outras seguiron estudos artísticos de distinto carácter ou prepararon oposicións. Incluímos tamén a varias mulleres que, sen nacer en Galicia, tiñan fortes vínculos ca nosa comunidade. As agrupamos por especializacións para seguir mellor as súas traxectorias:

\section{Pedagoxía}

Neste eido destacan as alumnas da Escola Superior do Maxisterio. $M^{a}$ Isabel Barreiro Fernández estudou na devandita Escola entre 1927 e 1930 (19ª promoción). Era filla dun notario de Vilagarcía de Arousa e casou con un residente ${ }^{17}$ membro do corpo diplomático. Dende a súa incorporación a Residencia ata 1931 traballou como profesora na sección de párvulos do Instituto-Escuela, o cal indica unha forte aproximación a María de Maeztu, directora desa sección. En marzo de 1930 deu unha conferencia sobre "Costumbres gallegas» na Residencia, dentro dun ciclo que nese curso se organizou sobre costumes das diferentes rexións españolas. Trátase dunha residente que viviu cinco anos en Madrid e que participou de cheo na vida da Residencia e do seu ambente.

Pura Cendán González viviu na Residencia entre 1921 e 1927. Natural de Ferrol, desprazouse a Madrid para estudar na Escola de Estudios Superiores do Maxisterio; tras dous anos preparando o ingreso, accedeu ao codiciado centro en 1923, rematando os estudos na sección de Ciencias en 1927. Solicitou participar no cursiño especial de 1934 para ingresar na Sección de Pedagoxía da Facultade de Filosofía e Letras de Madrid, dentro do cupo de mestres de primeira enseñanza normal. Casou con Jesús Jaraiz e morreu en Madrid o 25 de maio de 1983.

15 Como a Escola de Bibliotecàries, pioneira en España, e a Escola d'Enfermeres. Moi importante foi 0 Institut de Cultura i Biblioteca Popular de la Dona, creado en 1909 por Francesca Bonnemaison, ou iniciativas pedagóxicas como as de Rosa Sensat (Escolas do Bosque) o la Escola Nova seguidora do método Montessori. Véase: González-Agàpito, Josep et at. (2002), Tradició i renovació pedagógica 1898-1939: Història de l'educació. Catalunya, Illes Balears, País Valencià, Barcelona, Institut d'Estudis Cataláns, pp. 367-676.

16 Pérez-Villanueva Tovar, Isabel (1990), La Residencia de Estudiantes. Grupos universitario y de señoritas. Madrid 1910-1936, Madrid, MEC, p. 146.

17 Os matrimonios entre residentes do Grupo Masculino e Feminino non foron raros por razón de proximidade, cas salvedades que nesa época se poñían as relación entre os sexos. 
Concepción Fernández López, natural de Lugo, mestra, viviu na Residencia dende 1928 ata 1935. Era filla de Antonio Fernández Fernández (Antón de Marcos), empresario sarrián que fixera fortuna co tráfico de gando. Os catro fillos de Antón de Marcos ${ }^{18}$ (Antonio, José, Manuel e Concepción) estudaron carreiras superiores en Madrid; Concepción, orientada polo seu irmán maior e titor dende 1931, viviu na Residencia de Señoritas e colaborou en tarefas docentes na sección primaria do Instituto-Escola. Conchita, xunto cos seus irmáns, participou nunha serie de iniciativas empresariais senlleiras en Galicia, como Zeltia, Frilugo, Frigsa, Pescanova, etc. E no ano 1950 fundaron o Colexio Fingoi en Lugo, acolléndose á Lei de Centros Experimentais que permitía a posta en práctica de iniciativas de reforma pedagóxica; o primeiro director do Colexio Fingoi foi Ricardo Carballo Calero, e nas súas aulas impartiron clase intelectuais como Xosé Luis Méndez Ferrín ou Bernardino Graña. A memoria dos irmáns Fernández López se perpetúa con unha pequena praza de Lugo, na traseira do Museo Provincial, que leva o nome de Praza Fillos de Antón de Marcos. Méndez Ferrín recorda con emoción o seu paso como docente polo Colexio Fingoi:

Fingoi, nos sesenta, era unha illa de luz. Inspirado polas ideas do seu fundador, representaba un espacio de libertade e disciplina e estaba animado por un espírito de avanzada e de contemporaneidade excéntrico no panorama desolador do ensino primario e medio daqueles anos.

\begin{abstract}
A subordinación dos contidos aos ciclos da natureza, a unión de traballo manual e intelectual, a ausencia de libro de texto, as excursións educativa, a concepción máis ben liberal da pedagoxía, a coeducación dos sexos, o galeguismo e o progresismo que se respiraba en toda a vida do colexio, a insistencia no teatro e nas actividades, todo, e máis, configuraba un centro de ensino que se distinguía, fortemente individualizado, de todos os demáis. Fingoi, como o Estudio de Madrid, dirixido por Jimena Menéndez Pidal, continuaba en pleno franquismo o espírito da Institución Libre de Enseñanza e do Instituto Escuela fundado por Francisco Giner de los Ríos e aniquilado pola barbarie fascista e católica. ${ }^{19}$
\end{abstract}

Piedad Fernández López, naceu en 1900 en Castro Caldelas (Ourense), viviu na Residencia entre 1919 e 1924: preparou o ingreso na Escola de Estudios Superiores de Magisterio, na que ingresou en 1921, graduándose en 1924, na sección de Ciencias. Por Orden de 10 de maio de 1926 foi nomeada auxiliar de Pedagoxía da Escola Normal de Mestras de Baleares, con un soldo anual de mil quinientas pesetas. En xullo de $1929 \mathrm{Pie}$ dad Fernández escribe a María de Maeztu unha carta sobrecolledora na que lle pide que a recomende para unha das plazas de repetidora de español nunha Escola Normal francesa que todos os anos concede a JAE; di Piedad Fernández:

Yo tengo un interés enorme en conseguir esa plaza porque, sin ser un puesto brillante, es una gran solución para mí, que tengo que ganarme la vida dando lecciones particulares

18 Os irmáns Fernández López amosaron sempre un fondo amor a Galicia, plasmado na súa militancia na Mocedade Céltiga, xunto a Fermín Penzol, Viqueira e outros. Véase: Porto Ucha, Ángel S. (1986), La Institución Libre de Enseñanza en Galicia, Sada, Ediciós do Castro, p. 357.

19 Méndez Ferrín, Xosé Luis (2001), Un escritor nos xornais: artigos periodísticos, Santiago de Compostela, Universidade de íd., p. 113. 
y gracias a Dios estoy admirablemente de salud, pero cuando tengo que sustituir a la profesora y con mis lecciones tengo un trabajo horrible y temo volver a enfermar.

Yo no sé si V. recuerda, señorita de Maeztu, que estoy en Palma de Mallorca de auxiliar de Pedagogía, pero para sostenerme necesito dar lecciones y es un trabajo horroroso, pero afortunadamente de salud no puedo estar mejor; ya llevo tres años tan bien que mi curación sólo se explica o por un milagro o por una equivocación afortunadamente del médico. ${ }^{20}$

María de Maeztu atendeu a petición da súa antiga discípula, posto que a Comisión executiva da JAE acorda 02 de agosto de 1929 concederlle consideración de pensionada e unha axuda de quinientas pesetas e nomeala repetidora na Escola Normal de Mestras de Carcasonne durante o curso 1929-1930. ${ }^{21}$

Carmen Pardo Losada naceu en Ourense en 1890; pertenceu á quinta promoción (1913-1916) da Escola de Estudios Superiores do Maxisterio, sección Labores. En 1916 obtivo praza de profesora de Pedagoxía e a súa historia, Rudimentos de Dereito e Lexislación escolar na Escola Normal de Mestras de Lugo, da que foi directora dende 03 de setembro de 1916 ata 08 de xuño de 1931, cando a República destituiu ao claustro; recuperou o seu cargo en 1939 para ocupalo ata a súa xubilación en 1959.

Viviu tres anos na Residencia, entre 1925 e 1928. En 1919 foi admitida como socia do Instituto de Estudos Galegos de A Coruña. En 1930 foi nomeada vocal da Xunta especial de autoridades de ensino primario. Foi becaria da Universidade Internacional de Santander en 1933 e en 1935 e da Universidade Católica de Santander en 1934. O 9 de abril de 1935 asumiu a dirección da Escola Elemental do Traballo, cargo que ocupou ata abril de 1936. Foi tamén vocal da Xunta provincial de ensino primario de Lugo.

Carmen Pardo organizou as escolas graduadas anexas á Escola de Maxisterio de Lugo e formou parte do Padroado de Cantinas e Colonias escolares. Se lle concedeu a Gran Cruz da Orden de Alfonso X o Sabio e a consideración de directora honoraria da Escola de Maxisterio Feminina de Lugo. Morreu en Madrid en 1983. ${ }^{22}$

\section{Ciencias}

No ámbito das universitarias que seguiron a carreira de Ciencias destaca Ángeles Alvariño González, que naceu en Serantes (Ferrol) en 1916. Filla dun médico, amosou dende nena grandes inquedanzas intelectuais. Estudou en Ferrol e en Santiago; en 1934 se trasladou a Madrid para cursar a carreira de Ciencias, aloxándose na Residencia de Señoritas ata 1936, cando a guerra civil interrumpeu os seus estudos, que reanudou en 1941, xa casada co capitán da Mariña de Guerra Eugenio Leira Manso. Entre 1941 e 1948 deu clases de bioloxía e botánica en centros de Ferrol. En 1951 gañou unha praza de

20 A.R.S.M. Correspondencia Xeral: Carta de Piedad Fernández López a María de Maeztu, Castro Caldelas 1 de xullo de 1929.

21 Arquivo JAE. Expediente JAE/53-175.

22 Méndez Lois, Mํa José (coord.) (2009), Mulleres na educación en Galicia, Santiago de Compostela, MUPEGA, pp. 199-200. 
bióloga-oceanógrafa no Instituto Español de Oceanografía de Vigo. Dous anos despois o British Council lle concedeu unha bolsa para estudar o zooplancton no laboratorio de Plymouth. Participou en expedicións científicas no Atlántico e no Pacífico a bordo de buques oceanográficos británicos, estadounidenses e españois. Descubriu vintedúas especies de organismos mariños, como a hidromedusa Lizzia alvarinoae, que leva o seu nome. Publicou numerosos artigos científicos ${ }^{23}$ e recibiu en vida importantes recoñecementos, como a Medalla de Plata de Galicia en 1993. Morreu en San Diego (California) o 29 de maio do 2005. 024 de febreiro de 2012 o Instituto Oceanográfico de España botou en Vigo un moderno barco destinado a investigación ao que se deu o nome de Ángeles Alvariño, en homenaxe a destacada bióloga.

Consuelo Castelao Bernárdez naceu en Ourense en xaneiro de 1906, filla dun artesán. En 1926 comezou a carreira de Ciencias en Santiago e catro anos despois solicitou 0 traslado para Madrid. Viviu na Residencia entre 1931 e 1935.

\section{Farmacia}

As estudantes de Farmacia foron numerosas na Residencia, pero non as galegas, xa que en Santiago había unha Facultade arraigada que atraía a alumnos e alumnas do norte de España. Non obstante, algunhas chegaron ata Madrid, ben por inclinación persoal ou para cursar o doutoramento.

Marina Peña-Rey Bouzas naceu en Viascón (Pontevedra) en 1915. Era filla do xinecólogo ourensán Manuel Peña Rey, discípulo de Varela Radío. Marina estudou Farmacia en Santiago e en 1933 trasladouse a Madrid para seguir os seus estudos, aloxándose na Residencia de Señoritas. Casou co ovetense Luis Fanjul Álvarez-Santullano ${ }^{24}$, que vivía na Residencia de Estudiantes «o que ven a ratificar a afirmación endogámica entre os que disfrutaban dos apéndices institucionistas" segundo Ricardo Gurriarán. ${ }^{25}$ Trala la guerra se exiliou co seu marido en México e alá morreu no ano 2002.

Celsa Pérez Moreiras naceu en León o 25 de Nadal de 1912, pero tiña fortes vínculos con Galicia. Estudou Farmacia en Santiago e foi axudante de Técnica Física na Facultade. En 1934 trasladouse a Madrid e se aloxou na Residencia; en 1935 colaborou co doutor Marañón e o seu grupo de investigación no estudio "Metabolismo mineral y del agua en la enfermedad de Addison" e traballou no Instituto de Patoloxía Médica do Hospital Xeral de Madrid. En 1935-36 foi axudante de clases prácticas de novo na Facultade de Farmacia

23 A relación dos seus traballos científicos pode verse no seguinte vínculo: HTTP://WWW.CULTURAGALEGA.ORG/ALBUM/ DOCS/74_OBRA-ANGELES-ALVARINO.PDF

24 Luis Fanjul se doutorou en Mediciña en Madrid en 1930. Becado pola JAE en Viena en 1931 e 1932, foi xefe do laboratorio de hematoloxía da Facultade de Medicina, dirixido polo doutor Pittaluga. Durante a guerra foi xefe dos servizos de sanidade do Corpo de Carabineros. Exiliouse en México en 1940, onde traballou en varios laboratorios farmacéuticos. En: Simón Lorda, David, "Os nomes do exilio (médico, republicano, galego)", Cadernos de Atención Primaria, vol. 17, ano 2012, p. 267.

25 Gurriarán, Ricardo (2006), Ciencia e conciencia na Universidade de Santiago (1900-1940): do influxo institucionista e a JAE á depuración do profesorado, Santiago de Compostela, Universidad de íd., p. 238. 
de Santiago, traballou co catedrático Aniceto Charro no laboratorio de Bromatoloxía e colaborou no Instituto de Estudios Rexionais de Santiago. Durante a guerra prestou servizos na Farmacia Militar de Santiago. Formou parte do Seminario de Estudos Galegos. Casou co avogado Ignacio Sancho Rosa, accionista da editorial Guadiana. Morreu en Madrid o 28 de xullo do 2010.

\section{Medicina}

A carreira de Medicina foi a primeira que chamou a atención das mulleres, tamén en España. Como no caso de Farmacia, Santiago contaba cunha Facultade de Medicina de longa tradición; por tanto, poucas foron as que chegaron a Madrid para ampliar estudos ou facer o doutoramento. Nembargante contamos con algún exemplo ilustrativo. Así, Paz Parada Pumar naceu en Ourense en 1905 no seo dunha familia liberal; seu pai era o veterinario Abelardo Parada e o seu tío o pintor Parada Justel. Estudou o bachalerato en Ourense e tres anos de Medicina en Santiago, onde destacou como alumna brillante. En 1925 se trasladou a Madrid e viviu na Residencia de Señoritas ata 1929, especializándose en análises clínicos tras ser a única muller que asistía as clases do doutor Calandre no laboratorio de Anatomía Microscópica da Residencia de Estudantes. En 1929 casou co doutor Julio Freijanes Malingre, pediatra, e o matrimonio instalouse en Lleida, onde o doutor Freijanes exercía como inspector de Sanidade. En 1932 se trasladaron a Lugo ata a guerra, cando 0 doutor Freijanes sufriu desterro en Astorga. Posteriormente a familia regresou a Ourense e Paz Parada abriu un laboratorio privado de análises clínicos que rexentou ata a súa xubilación ao tempo que se ocupaba dos seus cinco fillos. Morreu centenaria no ano 2005 en Ourense. Na actualidade unha rúa de Ourense leva o seu nome.

Ángeles Pardo Celada naceu en Becerreá en 1904, filla dun xinecólogo de ideoloxía liberal. En 1920 se trasladou a Madrid para estudar Odontoloxía e viviu dous cursos na Residencia. Decidiu logo estudar Medicina, especializándose en xinecoloxía e puericultura e ampliando estudos pola súa conta en Alemania en 1930. Ao seu regreso traballou como auxiliar de laboratorio do Dr. Negrín. A guerra a sorprendeu en Lugo en 1936. En 1940 abriu unha consulta privada en Lugo, que compaxinou co traballo na rede sanitaria pública.

Olimpia Valencia López naceu en Baltar (Ourense) en 1898, filla do industrial Anacleto Valencia Lama e de Teresa López Mandianes. Estudou Medicina en Santiago, licenciándose en 1925 co premio extraordinario. En 1925 trasladouse a Madrid para facer o doutoramento co doutor Recasens, catedrático de obstetricia. Viviu tres anos na Residencia, exercendo diversas tarefas para pagar a súa estancia; en 1926-27 deu clases de cultura xeral as residentes, e a ano seguinte foi médica do Instituto-Escuela. Olimpia Valencia chegou a Residencia recomendada por don Ramón Menéndez Pidal e polo reitor da Universidade de Santiago, Armando Cotarelo Valledor. Co seu tesón supo gañar o aprezo de María de Maeztu, que en 1930 a recomenda ao doutor Negrín, membro do tribunal da tese de Olimpia:

Me permito recomendarle con el mayor interés a la Srta. Olimpia Valencia que ha presentado su Tesis doctoral y ha de ser juzgada en estos días. Esta señorita estudió en la Residencia 
y desde hace unos años ejerce su carrera en Vigo con gran competencia. Tengo mucho interés por ella pues es una excelente muchacha inteligente y trabajadora; la entrego, por lo tanto a su solicitud. ${ }^{26}$

A JAE lle concedeu a consideración de pensionada para visitar durante un mes clínicas xinecolóxicas en Alemania e Suiza ${ }^{27}$ para investigar no tema da súa tese, $A$ colesterina no sangue das operadas en relación ca anestesia quirúrxica. Afín a círculos galeguistas, foi detida en 1937 e salvouse polas boas referencias que dela deron persoas influentes de Vigo. Ela mesma confesou anos despois a súa experiencia:

Por el hecho de ser mujer nunca tuve problemas para ejercer mi profesión, pero sí encontré dificultades en la sociedad viguesa por mi afinidad con el Partido Galeguista, aunque yo no era realmente política. ${ }^{28}$

Foi médico do seguro nacional de enfermidade a partir dos anos 40 e exerceu a medicina privada en Vigo ata a súa xubilación na súa consulta da rúa do Príncipe no 11. Morreu na cidade olívica en 1987. Pouco antes do seu pasamento declarou con excepcional lucidez:

Aun ahora intento decir a las chicas jóvenes lo importante que es la independencia profesional y personal, la defensa de los ideales, aunque sé muy bien que los hombres de hoy siguen sin aceptar totalmente a las mujeres que son de verdad independientes, no a las que lo aparentan. Pero lo más importante es mantenerse fiel a una misma a pesar de todo y de todos..$^{29}$

\section{Filosofía e Letras, Arquivos e bibliotecas}

A carreira de Filosofía e Letras, considerada complementaria doutras no caso dos varóns, feminizouse moi pronto por entender que era especialmente adecuada a sensibilidade feminina, sobre todo cando se orientaba ao traballo en arquivos e bibliotecas. Entre as galegas ou mulleres relacionadas con Galicia que a escolleron destaca Blanca Dopico de Guernica, natural de La Habana, filla de galegos; estudou no colexio Concepción Arenal do Centro Galego de La Habana, onde recibiu unha completa formación. En 1928-29 viviu na Residencia mentres estudaba Filosofía e Letras en Madrid. Posteriormente foi profesora de Literatura Española e Linguas Modernas Estranxeiras na Facultade de Filosofía e Letras da Universidade da Habana. ${ }^{30}$

Raquel Lesteiro López naceu 029 de agosto de 1902 en Pontevedra. Estudou Filosofía e Letras e no curso 1921-22 trasladouse a Madrid, aloxándose na Residencia de Señoritas

26 A.R.S.M. Correspondencia de la Dirección: Minuta de carta de María de Maeztu a Juan Negrín; Madrid, 3 de noviembre de 1930.

27 Sesión de 4 de mayo de 1930. Archivo JAE. Expte. JAE/146-15.

28 Caldero, Sara, "Olimpia Valencia, primera gallega que estudió Medicina en Santiago", Faro de Vigo, 7 de decembro de 1986.

29 Ibíd.

30 Vida Gallega. Órgano Oficial de la Sociedad de Beneficencia de Naturales de Galicia. La Habana, enero 1957. 
ca súa irmá Celia, que aproveitou para estudar Corte e Confección. Mentres preparaba as oposicións ao corpo facultativo de arquivos e bibliotecas, en 1926 deu clases nos cursos trimestrais para estranxeiros do Centro de Estudos Históricos e en 1927 foi aspirante ao maxisterio secundario na sección de Letras do Instituto-Escuela ${ }^{31}$. En 1933, cando era auxiliar do corpo facultativo de arquivos con destino na Biblioteca Provincial de Cáceres solicitou a excedencia para colaborar na sección de Estudos Hispano-americanos do Centro de Estudios Históricos creada por Américo Castro. En 1944 foi destinada ao Arquivo da Delegación de Facenda en Pontevedra e posteriormente acadou a dirección do Arquivo Provincial de Pontevedra.

Luisa Cuesta Gutiérrez era natural de Medina de Rioseco (Valladolid) e estudou Filosofía e Letras en Valladolid. En 1921 accede por oposición ao corpo facultativo de arquivos e bibliotecas, con destino na biblioteca universitaria de corpo facultativo de Santiago, onde permanece ata 1930. En Santiago prestou atención aos fondos da Biblioteca América e desenvolveu unha importante labor de catalogación, investigación e difusión, como os artigos «La Universidad gallega: su pasado, su presente y su porvenir» (Boletín de la Universidad de Santiago de Compostela, 1930), ou «La emigración gallega a América» (Arquivos do Seminario de Estudos Galegos, 1932). Viviu na Residencia en 1927-28, mentres preparaba oposicións a Xeografía e Historia do Instituto San Isidro de Madrid. En 1930 foi trasladada a Biblioteca Nacional. Ao estalar a guerra, foi nomeada vogal da Comisión Xestora do Corpo Facultativo de Arquivos, Bibliotecas e Museos, presidida por Tomás Navarro Tomás; en 1937 encargouse da dirección da Biblioteca Nacional, destacando a súa labor de protección do patrimonio e dos tesouros bibliográficos. A derrota republicana supúxolle un expediente e o destino ao Arquivo de Facenda de Guadalajara; pasou logo a Biblioteca da Escola de Peritos Industriais de Madrid, e en 1945 é readmitida na Biblioteca Nacional. Xubilouse en 1962 como xefa da sección de Hispanoamérica da Biblioteca Nacional. Morreu en Madrid ese mesmo ano.

Rosa Solórzano Gutiérrez, natural de A Coruña, viviu na Residencia en 1934-35. Funcionaria do corpo facultativo de arquiveiros, bibliotecarios e arqueólogos con destino no Arquivo da Delegación de Facenda de Madrid e de Valladolid. Morreu na Coruña en 1980. Carmen Bugallo Orozco, natural de Pontevedra, foi profesora de Xeografía e Historia no instituto de ensino medio de Pontevedra nos anos 40 e 5032; o seu irmán Emilio exerceu de arquitecto municipal de Vigo dende 1941 e firmou numerosas obras na cidade olívica, como o espazo de homenaxe aos caídos no Castro; outro irmán, Antonio Rogelio, militar, correu unha sorte moi distinta pois foi depurado trala guerra e separado do exército por inxurias e desobediencia.

31 Archivo JAE. Expte. JAE/85-137

32 Xosé Fortes (coord.), O instituto de Pontevedra. Século e medio de Historia, Pontevedra, Diputación de íd., 1997, p. 162. 


\section{Música e estudos artísticos}

As que aspiraban a unha formación musical completa tiñan que acudir a Madrid para estudar no Conservatorio Superior de Música e Declamación. Na Residencia houbo sempre un pequeno grupo de mulleres que frecuentaban o devandito centro; foi o caso da galega Alejandrina Loureiro, residente entre 1930 e 1932, e soprano que se formou co profesor Ignacio Tabuyo.

Salientable é o caso de Sofía Novoa Ortiz, que naceu en Vigo en 1902. Viviu na Residencia entre 1918 e 1925 e entre 1930 e 1935, chegando a ser unha das persoas máis próximas a María de Maeztu. Sofía Novoa era filla de Joaquín Novoa Barros, xerente dunha consignataria de buques, articulista no diario vigués La lucha e presidente da Conxunción Republicano-Socialista de Vigo; Joaquín Novoa movíase no círculo de Fernando García Arenal, quen sen dúbida recomendou a Novoa que enviase aos seus fillos Francisco e Joaquín $^{33}$ a Residencia de Estudantes e a Sofía a de Señoritas. Polo tanto se trata dunha rama do frondoso árbore da Institución Libre de Enseñanza en Galicia. ${ }^{34}$

Sofía Novoa estudou Solfexo e Piano no Real Conservatorio de Madrid, obtendo o diploma de primeira clase no concurso de piano de 1923. Rematou a carreira de harmonía en 1925, con premio extraordinario. A continuación, se especializou en Lisboa con Vianna da Motta, Cerva y Rei Colaço (1925-28), a expensas da súa familia. En 1931 viaxou a París para estudar técnica e composición con Alfred Cortot e Nadia Boulanger, e a partir de entonces se encargou das clases de ximnasia rítmica no Instituto-Escuela, da dirección do grupo de Rafael Calvo (con capacidade para setenta residentes), e asumiu ademais a partir de 1934 as de Historia da Música na Residencia de Señoritas e a dirección da sección Artístico-Musical da Asociación de Alumnas. Unha actividade verdaderamente notable que se reflexa na abundante correspondencia que intercambiaron María de Maeztu e Sofía Novoa ${ }^{35}$.

En 1936 Sofía Novoa era profesora de Música e Cancións da sección preparatoria de Instituto-Escuela, a JAE lle acababa de conceder unha pensión para asistir a un curso de interpretación en París e outro de Nadia Boulanger no Conservatorio de Fontainebleau, pero a guerra lle impediu disfrutar da axuda. En xullo de 1937 partiu do porto de Vigo rumbo a Estados Unidos para desempeñar o cargo de auxiliar da sección de Folclore Hispanoamericano na Universidade de Columbia. En 1940 se instalou en Vassar College, unha selecta Universidade de mulleres americana que tivera fortes lazos ca Residencia de Señoritas, e alí permaneceu ata a súa xubilación en 1967, coincidindo con intelectuais

33 Francisco Novoa Ortiz estudou inxeniería e foi axudante de obras públicas en Vigo. O seu irmán Joaquín non rematou os estudos de inxeniería; despois da guerra traballou na empresa Zeltia, fundada polos irmáns Fernández López.

34 Maxistralmente estudado polo profesor Ángel Serafín Porto Ucha no seu senlleiro libro citado na nota 18 en un posterior traballo, La Institución Libre de Enseñanza y la renovación pedagógica en Galicia (1876-1936), Sada, Ediciós do Castro, 2005

35 A relación entre Sofía Novoa e a Residencia, representada por María de Maeztu, foi estudada de xeito orixinal por Elvira M. Melián no seu artigo «María de Maeztu Whitney y Sofía Novoa Ortiz (1919-1936), cultivar la salud, cultivar el espíritu, cultivar la lealtad", Circunstancia, año V, n-14, septiembre 2007. 
como Jorge Guillén, Pedro Salinas ou a familia de García Lorca. En 1950 regresou puntualmente a España para ler a súa tese, El amor en el romancero viejo, dirixida por Rafael Lapesa. Xubilouse en 1967 e regresou a España, asentándose en Madrid, aínda que pasaba os veranos en Vigo. Nesa época integrouse na AEMU (Asociación Española de Mulleres Universitarias), da que formaban parte antigas residentes e mulleres do círculo do Colexio Estudio. Morreu en Madrid en 1987; logo de ser incinerada, os seus restos foron trasladados ao panteón familiar de Cangas, cumprindo a súa vontade.

A pintora Maruja Mallo é ben coñecida. O seu verdadeiro nome era Ana Mํa Gómez González. Naceu en Viveiro o 5 de xaneiro de 1902. Ao pouco tempo a súa familia se trasladou a Avilés, onde o pai era funcionario do Corpo de Aduanas. En 1922 Maruja ganou unha beca da Diputación de Lugo para estudar en Madrid e se matriculou na Real Academia de Belas Artes de San Fernando e na Academia Libre de Julio Moisés, onde coñeceu a Salvador Dalí, que a introducirá no círculo de xóvenes artistas e intelectuais da xeración do 27 e a Residencia de Estudantes (Lorca, Alberti, Buñuel).

Moi amiga da poetisa Concha Méndez e da filósofa María Zambrano, Maruja causou sensación no Madrid nos anos 20 polo seu estilo de vida despreocupado e alegre; frecuentou as tertulias da Residencia de Estudantes e do Café Pombo, animado por Ramón Gómez de la Serna. O seu estilo pictórico chamou a atención de Ortega, que lle ofreceu os salóns da Revista de Occidente para organizar unha primeira exposición na primavera de 1928; tivo grande éxito e comezou a colaborar en importantes publicacións como a Revista de Occidente ou La gaceta literaria.

En 1931 solicitou unha pensión da JAE para estudar correntes de decoración teatral en París. ${ }^{36} \mathrm{Na}$ capital francesa coñeceu a André Breton, Paul Éluard, René Magritte, Max Ernst, Joan Miró, Giorgio de Chirico, Picasso e Louis Aragon. De volta en España deu clases de Dibuxo no instituto de Arévalo e na Escola de Cerámica de Madrid. En 1935 viviu na Residencia de Señoritas, encargándose de dar clase de Dibuxo as residentes. Ao principio da guerra atopábase en Galicia cas Misións Pedagóxicas; pouco despois se trasladou a Portugal e a Arxentina. En 1938 publicou na Vanguardia un estremecedor relato sobre a represión falanxista en Galicia. ${ }^{37}$ A partir de 1938 viaxa por Chile, Uruguai, Brasil e Estados Unidos.

Regresou a España en 1964, pero xa non quedaba ninguén da súa época. Dedicouse entón a pintar y a dibuxar viñetas para a Revista de Occidente. Aparte da súa interesantísima obra pictórica, escribiu libros de arte e numerosos artigos. En 1982 se lle concedeu a Medalla de Ouro das Belas Artes. Morreu en Madrid o 6 de febreiro de 1995, aos 93 anos. ${ }^{38}$

36 Archivo JAE. Expte. JAE/69-581

37 Maruja Mallo, "Relato veraz de la realidad de Galicia», La Vanguardia, Barcelona, 14/08/1938, p. 11; 16/08/1938, p. $4 ; 21 / 08 / 1938$, p. $11 ; 26 / 08 / 1938$, p. 5.

38 Mangini, Shirley (2001), Las modernas de Madrid. Las grandes intelectuales españolas de la vanguardia, Barcelona, Península. Sobre Maruja Mallo existe unha amplísima bibliografía, que estudia tanto a súa obra como a súa vida. De interese, pola súa amplitude, son: Congreso sobre Maruja Mallo: actas das xornadas realizadas 


\section{Outras orientacións}

Para rematar esta necesaria revisión falemos de Rita Fernández Queimadelos, que naceu en 1911 na Cañiza (Pontevedra). Estudou dous anos de Química na Universidade de Santiago e en 1930 se trasladou a Madrid para estudar Arquitectura, aloxándose na Residencia de Señoritas. Rematou a carreira despois da guerra, en setembro de 1940. Foi a segunda muller arquitecta de España, tras Matilde Ucelay. En 1941 comezou a exercer na Dirección Xeral de Rexións Devastadas, en Madrid; interrompeu a súa actividade profesional en 1946, ao nacer o seu cuarto fillo. En 1954 se trasladou a Murcia, onde foi arquitecta escolar provincial, arquitecta municipal de Mula e exerceu a profesión por libre na inmobiliaria CRISA. Posteriormente se trasladou a Barcelona, onde se xubilou en 1979 e onde morreu en setembro de 2008, aos 96 anos.

$M^{2}$ Luz Morales Godoy non pode ser considerada residente, senón máis ben amiga persoal de María de Maeztu. Frecuentou a Residencia en numerosas ocasións, cando visitaba Madrid, e potenciou os intercambios de alumnas entre a Residencia de Madrid e a Residencia Internacional de Señoritas Estudiantes de Barcelona, aberta en Barcelona en 1930 e ubicada no Pazo de Pedralbes, que ela dirixiu. Mª Luz Morales naceu na Coruña o 23 de abril de 1898; o seu pai, Juan Morales, era delegado de Facenda na cidade herculina, e por parte da súa nai estaba emparentada ca escritora e pedagoga María Barbeito y Cerviño ${ }^{39}$. A principios do século XX a familia Morales se traslada a Cataluña, onde queda fixada a súa vida. A morte prematura do pai a obriga a gañarse a vida co periodismo literario, colaborando en revistas femininas como El hogar y la moda e en periódicos como $\mathrm{La}$ Vanguardia. Entre 1926 y 1934 publicou no diario madrileño El Sol unha páxina semanal titulada «La mujer, el niño y el hogar». Durante a guerra dirixiu o xornal La Vanguardia «con carácter provisional, urgente y por plausibles razones de exclusivo servicio al periódico. Y desde luego, sin ninguna alteración en mis modestos emolumentos de simple redactora». ${ }^{40}$ Cando as tropas de Franco entraron en Barcelona, foi encarcerada durante un ano e pico e, logo, viviu en precario durante dous anos, sin poder firmar os seus traballos en prensa. Tras un período de ostracismo, en 1949 comezou a colaborar no Diario de Barcelona; escribiu numerosos libros, entre eles a novela Balcón al Atlántico (1955), na que recrea a súa infancia na Coruña, adaptou e traduciu libros para nenos, fundou a editorial Surco e traballou como editora na editorial Salvat. Si ben recibiu recoñecementos en vida (o Lazo de Dama de Isabel la Católica en 1971 ou o Premio de Periodismo "Ciudad de Barcelona" en 1972), non se resaltou, ata datas recentes, a súa inxente labor no mundo periodístico anterior a guerra civil e de educación da muller seguindo un modelo moi semellante ao da Residencia de Señoritas de Madrid. Mª Luz Morales, que mantiña unha fluída relación epistolar con María de Maeztu, manifestou o seu interese de crear en Barcelona unha

pola Dirección Xeral de Promoción Cultural en Viveiro en outubro de 2002, Santiago, Consellería de Cultura e Turismo, 2003. Huici, Fernando (ed.) (2009), Maruja Mallo, 1902-1995, Madrid, SECC.

39 Costa Clavell, Xavier, "María Luz Morales, ilustre escritora y periodista coruñesa», La voz de Galicia, A Coruña, domingo 8 de abril de 1979.

40 Ibíd. 
Residencia feminina similar a de Madrid; e así o di nunha carta que escribiu á pedagoga vasca en 1929:

Otra actividad que ahora se me lleva una parte del poco tiempo de que puedo disponer, es el propósito de fundación, aquí, de una Residencia similar a la de ustedes. La idea - confieso- no ha sido mía, sino de una señorita que estuvo en esa Residencia y que ahora es aquí empleada de Hacienda. Ella me ha empujado y con alguna otra mujer de buena voluntad estamos pasando por los innúmeros trámites y luchando con las infinitas dificultades que preceden en nuestro país a cualquier "obra" distinta de las que vienen haciéndose desde el tiempo de Maricastaña. Quisiéramos que el Ayuntamiento nos cediese uno de los Hoteles que en la Plaza de España se hicieron para la Exposición; quisiéramos sembrar una bonita obra de cultura... No sé, en fin, si todo ello se quedará en nada. ${ }^{41}$

A Residencia Internacional de Señoritas Estudiantes, dirixida por $M^{a}{ }^{-}$Luz Morales, abreu as súas portas en outubro de 1931 «con el loable propósito de resolver el problema del alojamiento de la señorita estudiante de fuera de Barcelona, así como el de la señorita dedicada al trabajo intelectual en general». ${ }^{42} \mathrm{~A}$ obra dependía dun Padroado integrado por representantes da Universidade Literaria, a Comisión de Cultura do Concello de Barcelona, o Consello de Instrucción Pública da Generalitat e outras entidades culturais barcelonesas. Polo tanto, o proxecto fíxose realidade, tomando como modelo a Residencia de Señoritas de Madrid.

A firme amizade entre María de Maeztu e $\mathrm{M}^{\mathrm{a}}$ Luz Morales plásmase en cartas que abundan en confidencias; especialmente impactante é a "confesión» que fai $M^{a}$ - Luz Morales á súa amiga en 1929:

El cultivo del huerto propio es, claro, lo primero, pero... usted, filosóficamente disciplinada, formada en un ambiente propicio a la seguridad y a la claridad intelectual, sabe certeramente cual es su huerto. Yo no. El periodismo es, sí, el pan y las medias de seda, la tranquilidad de mis viejos y la educación de mis chicos. Es también un poquito el deporte de un espíritu joven y muy femenino a quien asustan un tanto, por ceñudas, las empresas trascendentales... Pero fuera del periodismo jhay tantas cosas! $!^{43}$

O proxecto de Residencia dirixido por Mํㅡㄴ Luz Morales durante a República en BarceIona foi unha conxunción do modelo da Residencia de Señoritas de Madrid co das institucións cataláns que o sostiveron economicamente. Máis pequena que a Residencia de Madrid, a Residencia Internacional de Barcelona tivo un aire máis «burgués», combinando a formación intelectual (conferencias, concertos) con actos sociais como bailes de fin de curso que tiveron amplo eco na prensa barcelonesa da época.

Mํㅡㄴ Luz Morales morreu en Barcelona en 1980. Infatigable traballadora, un ano antes do seu pasamento traballaba nunha Historia Universal del Teatro en varios volumes.

41 A.R.S.M. Correspondencia Xeral. Carta de Mª Luz Morales a María de Maeztu, Barcelona 1929.

42 "La residencia internacional de señoritas estudiantes", La Vanguardia, venres 28 de agosto de 1931, p. 4.

43 A.R.S.M. Correspondencia Xeral. Carta de Mª Luz Morales a María de Maeztu, Barcelona 1929. 
$M^{a}$ Antonina Sanjurjo Aranaz naceu en Santiago o 6 de xullo de 1910, aínda que a súa familia estaba afincada en Vigo ${ }^{44}$ e pertencía ao círculo dos García Arenal, como a familia de Sofía Novoa. Perito e profesora mercantil, en 1931 trasladouse a Madrid para estudar na Facultade de Dereito e na Escola de Altos Estudos Mercantiles e se aloxou na Residencia de Señoritas, onde se aficionou a un deporte que introducirá en Galicia, o hóckey sobre herba feminino. En agosto de 1934 viaxa a Estados Unidos con unha bolsa para estudar en Smith College; pouco despois escribe a Pablo Martínez Strong, secretario da JAE, contándolle as súas favorables impresións: «Estoy encantada de verme en Smith, pues esto es espléndido y maravillosamente organizado. De la amabilidad de los americanos tendría para escribir un libro». ${ }^{45}$ Interesada en estudar Xeografía económica, en 1935 solicita una bolsa na School of Geography da Clark University (Worcester, Massachussetts) e se lle concede. No verano de 1936 regresa a España, pero ao poco tempo volve a Estados Unidos para dar clase de español no New Jersey College for Women; en 1938 rematou a súa tese titulada An Approach to the Colonial Evaluation of the French West Indies and French Guiana no Departamento de Xeografía da Clark University. Enfermou de tuberculose, e a súa nai a unha das súas irmás viaxaron ata Estados Unidos para acompañala de regreso a Galicia, onde faleceu 031 de outubro de 1939, aos vinte nove anos. ${ }^{46}$

Outras galegas que viviron na Residencia foron as irmás Dolores e Gerarda Gallego García, fillas do veterinario Abelardo Gallego Canel, dende 1903 catedrático de Patoloxía Médica e Terapéutica da Escola de Veterinaria de Santiago. Nos anos 20 traballou nos laboratorios da JAE en estreita colaboración con Pío del Río-Hortega; se lle considera o pai da histoloxía veterinaria española e un dos discípulos mais destacados de Cajal. Tivo oito fillos ca súa muller, Araceli García. Algúns deles estudaron na ILE de Madrid e no InstitutoEscuela; e dúas das súas fillas, Dolores e Gerarda viviron na Residencia de Señoritas. Dalgunhas mulleres pouco se sabe aínda; non todas as que viviron na Residencia desenvolveron posteriormente carreiras profesionais: algunhas casaron, as farmacéuticas se retiraban á cómoda seguridade das súas boticas, e outras foron cara o exilio. Este traballo pretende ser un primeiro acercamento a un tema no que queda moito que dicir.

A modo de conclusión aberta diremos que na Residencia de Señoritas de Madrid viviron, entre 1915 e 1936 un grupo de trinta e tres mulleres galegas ou con fortes vínculos en Galicia, o que supón $02,81 \%$ do total, é dicir, unha porcentaxe moderada que se explica fundamentalmente por motivos económicos (Ionxanía de Madrid) e estritamente académicos (lento acceso das mulleres galegas a educación superior, preferencia por estudar no distrito universitario de Santiago). A maior parte das galegas residentes procedían de familias de clase media acomodada, eran fillas de empresarios, médicos, veterinarios ou funcionarios, persoas que desexaban para as súas fillas unha educación esmerada e tiñan medios para pagala. Destaca o grupo de Vigo, ligado a familia García Arenal, e represen-

44 Era filla de Manuel Sanjurjo Otero e neta do recoñecido empresario Manuel Sanjurjo Badía.

45 Archivo JAE. Expte. JAE/134-290

46 López Villar, Cristina, "María Antonina Sanjurjo Aranaz. Pioneira do deporte galego e considerada "nai" do hóckey sobre herba en Galicia", en: HTTP://WwW.CULTURAGALEGA.ORG/ALBUM/DETALLE.PHP?ID=275 [consultado 11/12/2012] 
tado por Sofía Novoa Ortiz e Mํㅡㄹ Antonina Sanjurjo Aranaz, a primeira leal colaboradora de María de Maeztu na Residencia e a segunda unha xoven inquieta que ampliou os seus estudos en Estados Unidos e morreu prematuramente. Por provincias, Pontevedra foi a que mandou mais residentes a Madrid. Ningunha foi mais importante que as demais. Elas, e as que aínda non teñen nome, eran e sempre serán nosas. 